\title{
Tres Manifestaciones de Espacialismo Poético: Federico García Lorca, Nicolás Guillén y Jorge Luis Borges
}

A partir del siglo $\mathrm{xIx}$, en virtud de las teorías evolucionistas de Darwin, el determinismo científico de Taine y la medicina experimental desarrollada por Bernard, la ciencia y la filosofía han sostenido que el hombre es producto de su herencia y ambiente. No nos interesa esta premisa desde el punto de vista sociológico o moral, sino solamente para llegar a una interpretación de la poética -arte humano por excelencia.

En su obra Teoria de la expresión poética, Carlos Bousoño define la poesía como "comunicación" por medio de palabras, de una "síntesis intuitiva, única, de lo conceptual-sensorial-afectivo".1 A los efectos de nuestro estudio, nos interesan sobre todo dos aspectos de la síntesis poética: lo sensorial y lo afectivo. La imagen poética, por lo general, surge de la vivencia ambiental e individual del poeta; por ello el ambiente del poeta, su espacio vital, no es el trasfondo del poema, sino parte integral de su esencia. Este espacio le ofrece al poeta, desde su nacimiento hasta su muerte, formas, colores, impresiones y sensaciones, que él acumula en la memoria del subconsciente. ${ }^{2} \mathrm{Al}$ producirse el choque dinámico de la inspiración ante un hecho dado, llámesele objeto o tema, entran en juego estas asociaciones sumergidas que enriquecen la creación. Se hacen partes constitutivas de la composición poética, aunque son más evidentes en unos poemas que en otros.

La explicación de cómo el espacio llega a ser sustancia poética por excelencia, la ha dado Gastón Bachelard en su obra, La poétique de l'es.

1 Carlos Bousoño, Teoría de la expresión poética, Madrid, Editorial Gredos, S. A. 1966 , p. 19.

2 Para Bousoño, también el poeta es un "genérico creador" que "construye su obra desde las posibilidades que le ofrece un material cargado de exigencias". Op. cit., p. 32 . 
pace (1957). Del arte del poeta depende el éxito del experimento creativo; según Bachelard, "cuando la imagen es nueva el mundo es nuevo". ${ }^{3}$

Entre el poeta y su creación -el poema- existe una dialéctica que muchas veces es imposible interpretar; crea su propio espacio y es la expresión de un devenir del cual participa el lector en lo profundo de su ser; esto es, cuando el poema dice algo al recipiente, éste se siente por unos momentos transportado a ese espacio intangible, que ya no pertenece al poeta, sino a "su" poema. ${ }^{4}$

Según Emilio de Matteis en su obra El ser y el espacio, "el espíritu del hombre es lo único del ser humano que escapa -cuando la intención cognoscitiva se lo propone - a la presión y no sólo de las fuerzas físicas categoriales, sino también a la influencia de los planos"; $;$ o sea, que el hombre puede trascender su realidad espacial por la fuerza de su intelecto; $y$ sin duda por su sensibilidad poética.

Dentro de esta perspectiva, analizaremos tres composiciones poéticas de tres conocidos poetas del siglo $\mathrm{xx}$, un español y dos hispanoamerica. nos, los cuales han tomado la guitarra como tema. Los tres poemas coinciden en el motivo y en el título, pero ahí cesa su similitud. Son muy diferentes las concepciones poemáticas que este instrumento musical ha provocado en el ánimo de los autores. $\mathrm{L}_{a}$ recreación poética de la guitarra, vista desde tres perspectivas muy diferentes, refleja hasta qué punto herencia y ambiente se conjugan inevitablemente para influir en sus creaciones.

Del mundo gitano, de la Andalucía policroma y efusiva, brota el poema de Garcia Lorca:

\section{LA GUITARRA}

Empieza el llanto

de la guitarra.

Se rompen las copas

de la madrugada.

Empieza el llanto

${ }^{3}$ Gastón Bachelard, La poética de l'espace, Paris, Presses Universitaires de France, 1967, p. 7.

4 Según Octavio Paz: "abierto o cerrado, el poema exige la abolición del poeta que lo escribe y el nacimiento del poeta que lo lee". Corriente Alterna, México. Siglo XXI Editores, S. A., 1968, p. 72.

5 Emilio de Matteis, El ser y el espacio, Buenos Aires, La mandrágora, 1966 , p. 94. 
de la guitarra.

Es inútil callarla.

Es imposible

callarla.

Llora monótona

como llora el agua,

como llora el viento

sobre la nevada.

Es imposible

callarla.

Llora por cosas

lejanas.

Arena del Sur caliente

que pide camelias blancas.

Llora flecha sin blanco,

la tarde sin mañana,

y el primer pájaro muerto

sobre la rama.

Oh, guitarra!

Corazón malherido

por cinco espadas. ${ }^{6}$

En esta personificación de la guitarra, el instrumento ha sido vivificado, humanizado por la expresión musical de la congoja. La música arrancada a las cuerdas de la guitarra es, para García Lorca, un llanto que encuentra su expresión definitiva en el "cante jondo", voz de queja lejana, de dolor anciano, de deseperanza eterna.

La guitarra del poeta andaluz está enraizada en el ambiente de su creador, Andalucía cálida y pintoresca que expresa los instintos más elementales en el tablado y en el ruedo, donde el cantaor y el torero representan el alma regional; ésta batiéndose con la muerte heroicamen. te, aquél cantando su heroísmo; pena existencial, mezcla de erotismo, violencia y orgullo.

El tono del poema es narrativo, persistente, quejoso, una angustia contenida lo permea. Nacido de vivencias y paisajes andaluces, nos arrastra de la abierta página escrita a su espacio único. En el primer verso, García Lorca nos da una palabra clave, "llanto", cuyo significado matiza la composición y que, desarrollada, constituye el poema. La visión

- Federico García Lorca, Antología poética (1918-1936) Buenos Aires, Editorial Losada, 1957, p. 33. 
total de la guitarra está proyectada en torno al sonido del llanto; la guitarra llora y "es imposible callarla". Llanto y silencio, llanto y silencio, le dan a los versos un ritmo peculiar, una persistencia espacial y sensorial. Cuando la guitarra llora, "se rompen las copas de la madrugada", lo que debía ser efecto visual, la aparición de la luz al amanecer, se concibe sinestésicamente como efecto auditivo, al quebrarse el cristal continente del color. El "llanto" "empieza" siempre con cada verso, como si hubiera silencio, pero las negaciones implícitas que siguen: "Es inútil callarla" y "Es imposible callarla", que se repite en versos posteriores, muestran su persistencia ineludible. La paradoja crea la sensación de perdurabilidad. "Empieza el llanto", pero "es inútil callarla". Se intensifica este efecto con los versos cortos, interrumpidos por las causas obligatorias de la puntuación, como en los versos siguientes en que el ritmo se alarga y se ajusta a las imágenes que desarrolla al introducir las concepciones espaciales de "agua" y "viento", para compararlas con el sonido del llanto de la guitarra. La comparación es el grado más sencillo de la escala metafórica. Aquí también contrasta la blancura estática de la nieve que permanece impasible ante el dolor de los elementos:

Llora monótona
como llora el agua,
como llora el viento
sobre la nevada.

Todos los verbos del poema están en el tiempo presente y en tercera persona del singular, excepto uno, "rompen". El uso de este tiempo verbal crea un ambiente existencial, y el poema se sitúa fuera del tiempo por el llanto intemporal de la guitarra. "Llora" siempre está stiuado en aná. fora, y se repite cinco veces en esta posición. También hay cuatro verbos impersonales: "es inútil", "es imposible" (dos veces), y "se rompen". La humanización del instrumento se reitera con estas construcciones, la guitarra parece actuar por sí sola. Esta característica la ha señalado Concha Zardoya en su estudio "La técnica metafórica de Federico García Lorca", en el que cita varios poemas inspirados por la guitarra que tienen la humanización como característica en común.7

García Lorca emplea muy pocos adjetivos: "lejanas", "caliente", "blancas". todos sensoriales; "monótona", usado una vez como adverbio, modifica a "llora" y "primer", que se refiere a "pájaro"; dos participios, "muerto" y "malherido", también son usados como adjetivos.

7 Concha Zardoya, Poesía española contemporánea. Estudios temáticos y estilisticos, Madrid, Ediciones Guadarrama, 1961, p. 35i, 
Evidentemente lo que el poeta andaluz ha hecho es crear un poema que transforma el sonido de un instrumento musical en un espacio poético. "Arena del Sur caliente" es el único verso de la realidad ambiental andaluza; los elementos de "agua", "viento", "nevada", podrían ser de muchos otros mundos. La guitarra "llora" en sus notas, como el andaluz llora en su "cante jondo". Para García Lorca, guitarra-llanto es una dicotomía inseparable, y no por poética, menos real.

El ritmo del poema, inseparable del tema y la expresión, es parte, según Amado Alonso, de "una organización de sensaciones en una estructura dinámica". 8 Predomina la asonancia en "aa" y la combinación de "oa", vocales que abundan en todo el poema creando una intensa aliteración vocálica. Esta es otra manera de desarrollar el sonido y sentido de la palabra clave "llora" y su efecto "llanto".

El segundo poema, el del poeta cubano Nicolás Guillén, nos transporta a otra dimensión espacial y espiritual. Sangre mulata, ron, canela y són emanan ahora del instrumento. Es el trópico perezoso y envolvente, preñado de sensualidad y de cálida morosidad.

\section{GUITARRA}

Tendida en la madrugada la firme guitarra espera; voz de profunda madera desesperada.

Su clamorosa cintura en la que el pueblo suspira, preñada de són estira la carne dura.

Arde la guitarra sola mientras la luna se acaba; arde libre de su esclava bata de cola.

Dejó el borracho en su coche, dejó el cabaret sombrío, donde se muere de frio, noche tras noche,

8 Amado Alonso, Materia y forma en poesía, Madrid, Editorial Gredos, S. A., 1965, p. 275. 
y alzó la cabeza fina, universal y cubana, sin opio, ni marigüana, ni cocaina.

Venga la guitarra vieja nueva otra vez al castigo con que la espera el amigo, que no la deja!

Alta siempre, no caída, traiga su risa y su llanto; clave las uñas de amianto sobre la vida.

Cógela tú, guitarrero, límpiale de alcol la boca, y en esa guitarra, toca tu són entero.

El són del querer maduro, tu són enteto; el del abierto futuro, tu són entero;

el del pie por sobre el muro, tu són entero...

Cógela tú, guitarrero, límpiale de alcol la boca, y en esa guitarra toca, tu són entero. ${ }^{9}$

La situación temporal del poema del cubano es la madrugada, el final de la noche. En el primer verso su guitarra, "tendida en la madrugada", espera, y en el segundo verso de la tercera estrofa, "mientras la luna se acaba", arde. El español también había situado su composición poética en este tiempo al decir "se rompen las copas de la madrugada".

La guitarra de Nicolás Guillén posee la ardiente sensualidad de la

9. Nicolás Guillén, El són entero. Cantos para soldados y sones para turistas, Buenos Aires, Editorial Losada, S. A., 1968, pp. 49-51. 
naturaleza tropical. Simbólicamente, para el poeta cubano, la guitarra es, desde los primeros versos, una mujer apasionada: "Tendida en la madrugada"... "espera", "desesperada", con la "voz de profunda madera". Es como si fuera un ser humano, esperando que su destino se realice a manos de otro.

El poema tiene una construcción uniforme; las estrofas son de ciatro versos: tres octosílabos y uno de cuatro sílabas, todos de rima consonante, exceptuando la penúltima estrofa de seis versos, también consonantes, que forman un titmo diferente.

En la segunda estrofa, el poeta continúa con la imagen mujer guitarra. Esta vez le adjudica una "clamorosa cintura", y la ve como engendradora del "són", con la relación de madre-hijo, mujer encinta que dará a luzz el sonido.

En la tercera estrofa, Guillén mantiene la humanización de la guitarra, haciéndola capaz de sentir; el verbo "arde", repetido dos veces, unido a los adjetivos "sola" y "libre", reitera su innata capacidad emotiva, a pesar de su forzada vestimenta de la "bata de cola". Todos los verbos de las tres primeras estrofas se usan en presente. El tono es descriptivo, la guitarra no emite sonido, pero está "preñada de són", tiene la capacidad de darlo. El ambiente espacial que pinta Guillén es de interiores, "coche" y "cabaret". No hay tantos paisajes como en el poema de García Lorca.

La guitarra de Guillén, por propia volición, "dejó" en la cuarta estrofa espacios interiores que la deprimen: el "coche del borracho" y el "cabaret sombrio". En ellos era como una mala mujer que se prostituía perdiendo lo mejor de sí. Los verbos en el pretérito dan sensación de un pasado irrevocable.

En la quinta estrofa, el poeta mantiene a la guitarra en su actitud independiente: ésta quiere cumplir su destino, sin drogas, genuinamente "universal y cubana".

A partir de la sexta estrofa, cambia la proyección del poeta; la guitarra sin deshumanizarse, vuelve a objetivarse, es de nuevo el instrumento del "amigo" que la usa, siempre en forma nueva y diferente, aunque ella sea vieja. Los imperativos "venga" y "traiga" cambian el tono de la estrofa; ahora la guitarra puede expresar la alegría y la tristeza, es receptiva a todos los estados anímicos del hombre. Esta concepción de Guillén contrasta con la de García Lorca, quien sólo la envisiona con la capacidad de llorar.

$Y$ en las estrofas finales, Guillén expresa cuál es el destino de esa guitarra "universal y cubana"; tocar el "són entero", sobria y apasiona- 
damente, con los cinco sentidos puestos en el puro goce del ritmo que describe. Ritmo cálido, insistente, persuasivo, evocador de acentos africanos, primitivos, en los que el hombre olvida sus penas en el deleite de la danza: "Són del querer maduro" "del abierto futuro" "del pie por sobre el muro". Són de amor, de esperanza, de libertad. Todo culmina en el són "entero" y cubanísimo de Guillén.

Así como la herencia y el ambiente de García Lorca han influido en la recreación poética del "cante jondo", en el de Guillén el "són" cubano cálido y sensual crea su propio mundo: su ritmo construye imágenes y les da forma, color y sabor.

$$
\begin{aligned}
& \text { El són del querér madúro, } \\
& \text { tu són entéro; } \\
& \text { el dél abierto futúro, } \\
& \text { tu són entéro; } \\
& \text { el dél pie por sóbre el múro, } \\
& \text { tu són entéro... }
\end{aligned}
$$

Este ritmo es el del bongó, el de las maracas y el de la clave; es el del són cubano.

Y en la última estrofa, que es repetición de la octava, Guillén pide que en esa guitarra-mujer, de limpia voz, el guitarrero amante toque el "són" cubano, pues en éste se realiza mejor su destino.

Con el tercer poema, el del argentino Jorge Luis Borges, nos trasladamos por encima del tiempo y del espacio al horizonte ilimitado de la pampa, morada del gaucho, tierra de silencio y soledad.

\section{LA GUITARRA}

He mirado la Pampa

desde el traspatio de una casa de Buenos Aires.

Cuando entré no la vi.

Estaba acurrucada

en lo profundo de una brusca guitarra.

Sólo se reveló

al entreverar la diestra las cuerdas.

No sé lo que azuzaban;

a lo mejor fue un aire del Norte

pero yo ví la Pampa. 
Vi muchas brazadas del cielo sobre un manojito de pasto.

$\mathrm{Vi}$ una loma que arrinconan quietas distancias

mientras leguas y leguas

caen desde lo alto.

$\mathrm{Vi}$ el campo donde cabe

Dios sin haber de inclinarse,

vi el único lugar de la tierra

donde puede caminar Dios a sus anchas.

Vi la Pampa cansada

que antes horrorizaron los malones

y hoy apaciguan en quietud maciza las parvas.

De un tirón vi todo eso

mientras se desesperaban las cuerdas

en un complás tan zarandeado como éste.

(La vi también a ella,

cuyo recuerdo aguarda en toda música)

Hasta que en brusco cataclismo

se apagó la guitarra apasionada

y me cercó el silencio

y hurañamente tornó el vivir a estancarse. ${ }^{10}$

Al leer el poema de Borges, notamos inmediatamente dos cualidades: el tono expresivo-intelectual y el hecho de que la guitarra le sirve de trampolín para saltar a otra realidad, la pampa, que, agazapada en el instrumento, se devela con el sonido, se extiende hasta contener a Dios, y luego se recoge mágicamente en un silencio conclusivo.

En los dos primeros versos hay una superposición de espacios: el infinito, simbolizado por la pampa, y el cotidiano, la casa de Buenos Aires con su traspatio y su guitarra. "He mirado la Pampa/desde el traspatio de una casa de Buenos Aires". Como en el poema de Guillén, la guitarra espera para ser tocada; pero allí cesa el parecido. Para Borges, es sólo una "brusca guitarra", que al primer acorde, casual, "al entreverar la diestra las cuerdas", materializa la pampa. Por efecto sinestésico, el sonido trae vistas: "Vi brazadas del cielo", "una loma", "el campo", todo contenido en esa pampa de "leguas y leguas".

Dios le sirve de punto de partida para una comparación espacial -en

10 Jorge Luis Borges, Obras completas, II, Poemas: 1923-1958, Buenos Aires, Emecé, 1958, pp. 40-41. 
la pampa cabe Dios, pues es infinita su inmensidad; "cabe / Dios sin haber de inclinarse", y "puede caminar Dios a sus anchas".

La guitarra, con su sonido, también le trae a la mente una intemporalidad mágica. La "Pampa cansada" es la pampa de los caudillos y las montoneras, "los malones", que dejaron en ella su huella imborrable. Presente y pasado ahora son uno; la pampa de ahora está en la "quietud maciza" de sus sembrados; a pesar de estar casi todo el poema escrito en el pasado, la presencia de un Dios inmensurable en una infinita pampa, nos desconcierta y nos borra las nociones de un tiempo cronológico.

La visión intensa, pero fugaz, ha sido producto de un "compás zarandeado", conocido de Borges, que deja de ser al cesar el sonido.

Con un breve paréntesis "( La vi también a ella / cuyo recuerdo aguarda en toda música)" inserta una breve impresión de mujer, que podría muy bien representar la poesía, pero que queda dominada por la pampa, la cual absorbe todo el poema.

Los último cuatro versos rompen la trama mágica tejida por el sonido. Para Borges, el silencio es la vuelta de lo cotidiano al vivir sin dimensiones, con barreras de mutismo. La intemporalidad espacial del sonido es lo poético, lo: mágico, lo que hace que el hombre trascienda.

Hasta que en brusco cataclismo se apagó la guitarra apasionada y me cercó el silencio y hurañanamnete tornó el vivir a estancarse.

En su reciente artículo sobre "Los límites del arte en algunos poemas de Borges" Lewis H. Rubman estudia "La guitarra" e interpreta la visión de la pampa de Borges como una "hazaña propia de la imaginación poética; esta Pampa es una Pampa Poética... transforma la estrecha y agobiante realidad del traspatio en una ficción infinita y comprensible, siquiera por unos momentos". ${ }^{11}$

Sólo podemos sentir la calidad poética de este poema situándonos en la pampa argentina. Esta vez es paisaje-espacio lo que evoca el sonido. Ya no hay llanto, ni són, sólo el infinito "leguas y leguas", "brazadas de cielo" y "Dios" caminando "a sus anchas". Es una ficción infinita, pero, ¿es comprensible?

Borges, el de los fantásticos juegos mentales, nos muestra en su poema "La guitarra" otra fase, su innata religiosidad y nos hace parti-

11 Lewis H. Rubman, "Los límites del arte en algunos poemas de Borges", Mundo Nuevo, núm. 32, febrero 1969 , p. 55. 
cipes de una intima experiencia emocional en su infinita pampa: mágico espacio sin confines.

En el poema de García Lorca la música actualiza la experiencia intemporal. "Empieza el llanto / de la guitarra", y su sonido sostiene toda la concepción poemática. En el poema de Guillén la firme guitarra espera: Aún al final del poema no se ha hecho realidad el ruego del poeta al guitarrero: "Toca / tu són entero", sin embargo, ya intuimos este són entero, encerrado en la guitarra cubana, al leer los versos de Guillén que lo describen y recrean su sustancia ideal. Al empezar el poema de Borges, ya el poeta ha oído su "compás zarandeado". Su experiencia poética está enmarcada en el pasado, y por eso repite "vi" en nueve versos del poema. Aspira a resumir el espacio cósmico irreductible a una dimensión comprensible. Imposible por la razón, pero posible por la poesía.

La visión inmensurable de las llanuras infinitas de la pampa encuentra correspondencias en los espacios interiores del alma y la conciencia del poeta; a través del dinamismo kinético de su concepción poemática nos asomamos a este espacio creado, que desaparece con el último verso del poema.

Los tres poemas sugieren una objetivación poética tridimensional, que podríamos resumir en el siguiente esquema:

García Lorca:

guitarra

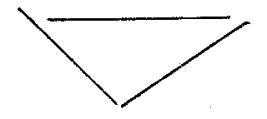

llanto

Guillén:

guitarra

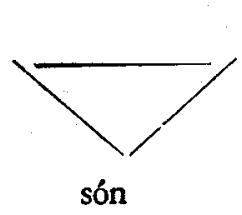

Borges:

guitarra hombre

mujer

Dios

\section{Pampa}


De los tres poemas el más melancólico es el de García Lorca, el más sensual el de Guillén, el más intelectual el de Borges. Lo poético ha tenido tres manifestaciones distintas, tres plasmaciones diferentes. Son creaciones representativas de los tres poetas, enraizados en sus tres espacios: España andaluza, Cuba y Argentina.

La guitarra crea en el espacio, con su sonido, tres sustancias únicas. Para García Lorca la congoja es su expresión innata; para Guillén es el ritmo del són que expresa la pasión amorosa, la libertad, la gozosa aceptación de la vida; para Borges es un espacio infinito, una pampa idealizada, casi metafísica, espacio creado dentro del hombre y a la vez más allá de él, que le atrae y le llama hasta sacarlo de su asfixiante realidad.

La estructura y el tema son inseparables en cada poema, pero la realidad, profundamente subjetiva ha sufrido una deformación al filtrarse en el tamiz artístico de la poética.

La objetividad concreta de la guitarra, que acarrea para cada poeta asociaciones intemporales y espaciales, se atomiza en el transcurso de los poemas y crea un haz de significados intensamente subjetivos en cada caso. Andalucía es ahora la impresión que García Lorca nos ha dejado; el són cubano es el que Guillén ha expresado; la visión de la pampa es la que ha sentido Borges interiormente con los ojos del espíritu. Los tres poemas crean espejismos poéticos, espacios sin tiempo e irrevocables experiencias por el ritmo y sentido de sus palabras.

El espacialismo poético viene a ser la otra forma de la forma, la visión de un universo nacida de esencias individuales, que resume y proclama sus raices.

Para los tres poetas, la guitarra es un medio de trascender; su sonido es la expresión de lo indecible. Las poesías interpretan en velados símbolos su sentir: sufrimiento humano, gozo de vida y contemplación del infinito. Espacios creados fuera del espacio, instantes que se disuelven en otros instantes, $y$ como ha poetizado el mismo Borges:

Más allá de este afán y de este verso

Me aguarda inagotable el universo.

George Mason College

María Teresa Font

of the Univresity of Virginia 